http://jmscr.igmpublication.org/home/ ISSN (e)-2347-176x ISSN (p) 2455-0450

crossref DOI: https://dx.doi.org/10.18535/jmscr/v9i5.31

\title{
Prevalence and risk factors of low back pain among health care providers in security forces hospital
}

\author{
Author \\ Dr Bandar Abdullah Al Agl \\ M.B.B.S, Family Medicine Consultant \\ Security Forces Hospital, Riyadh
}

\begin{abstract}
Background: Low back pain $(L B P)$ is a relatively ignored but highly prevalent clinical condition in adult population especially those working in some professions including health care. A number of risk factors are associated with the development of this condition, most of which are related to job.

Purpose: The purpose of this study was to find out the prevalence of LBP among health care providers in a security forces hospital - one of the largest Health institute in Riyadh, and to identify the risk factors associated with the LBP in this population.

Methods: It was a descriptive analytical cross sectional study involving 322 health care providers at Security Forces Hospital, Riyadh. Sample population was selected through stratified random sampling technique. Data about characteristics of LBP and various risk factors and demographic features was collected through structured question.

Results: Low back pain was reported by $75.2 \%$ of the health care workers (HCWs).Most of them (92.8\%) developed LBP after starting their job and $84.7 \%$ reported that the LBP was related to their work. Lifting objects, bad body postures and lack of knowledge about LBP were found to be significantly associated ( $p$ value $=0.001,0.002$ and 0.001 respectively) with LBP. Other risk factors were not associated with LBP significantly.

Conclusions: Self-reported low back pain was found highly frequent among healthcare workers. Practice regarding getting diagnosis and seeking modern treatment was found to be suboptimal. Significantly associated risk factors included lifting the objects or the patients, bad postures and lack of knowledge about lower back pain.

Keywords: health care workers, prevalence, low back pain, risk factors.
\end{abstract}

\section{Introduction}

Low back pain (LBP) is a very frequent, long standing, agonizing and yet vastly ignored clinical condition which affects $70-85 \%$ of adult population in almost any given area of the world, at least once in their life. ${ }^{(1)}$ The direct and indirect costs of LBP in terms of quality of life, productivity, and employee absenteeism are enormous, making this common condition the single largest contributor to musculoskeletal disability worldwide. ${ }^{(2-4)}$

LBP is associated with multiple risk factors, including gender, age, lifestyle, psychosocial profile, physical demands of the workplace, social support, and pain perception. ${ }^{(5,6)}$ A number of industries are said to have higher frequency of 
LBP among its workers as compared to age and gender matched general population of same geographical and racial backgrounds. ${ }^{(7,8)}$

Hospital workers seem to have higher rates of LBP compared to the general population due to physical and emotional factors involved in their occupation, such as stress. ${ }^{(9)}$ These rates are not well established in Riyadh. Hence, the purpose of this study was to estimate the prevalence of LBP among health care providers in a security forces hospital as one of the biggest Health institute in Riyadh, and to identify the risk factors associated with the LBP in this population.

\section{Literature Review}

El Sayyed et al. conducted a study in Ajman and Fujairahto investigate the prevalence of low back dysfunction in health professionals, and its relation to the nature of work and identify the risk factors associated. Data was analyzed using both descriptive and inferential statistics to estimate the prevalence of low back dysfunction in health professionals and to investigate relation between back dysfunction and hospital work. It was found that health care professionals whose nature of work involves more of trunk bending and manual lifts who reported of low back dysfunction were the same compared to health care professionals whose nature of work involved sitting and its variation and standing and its variation. While some differences have been noticed, statistically significant differences in low back dysfunction were not found among gender, age and also educational opportunities availed in back care. ${ }^{(10)}$

A cross-sectional survey among health professionals working in a hospital in Kuwait to investigate the prevalence and factors associated with low back pain Lifetime prevalence of LBP in the sample was $70.9 \%$, and point prevalence of LBP was $21.5 \%$. Factors associated with acute LBP included direct patient contact $(P=0.015)$, performing patient lifts and/or transfers $(P=$ $0.016)$, low job satisfaction $(P=0.039)$, and poor self-reported health status $(P=0.019)$. Other factors generally associated with LBP, such as age, sex, professional experience, smoking and exercise, were not found to be significantly associated with LBP in this study. ${ }^{(11)}$

A cross sectional study done in Iran, to investigate the prevalence and risk factors of LBP in surgeons and to analyze how individual and occupational characteristics contribute to the risk of LBP. The study was conducted on 250 randomly selected surgeons including 112 general surgeons, 95 gynecologists and 43 orthopedists from 21 hospitals at northern Iran. A structured questionnaire including demographic, lifestyle, occupational characteristics as well as prevalence and risk factors of LBP was used. Prolonged standing, repeated movements and awkward postures were the most prevalent aggravating factors $(85.2 \%, 50.2 \%$ and $48.4 \%$, respectively). Rest was found to be the most relieving factor $(89.5 \%)$. Further large scale studies, including other specialties and health professions such as physical therapy, chiropractic, and general medicine, should be performed. ${ }^{(12)}$

Study conducted to describe the prevalence and risk factors for lower back pain amongst a variety of Turkish hospital workers including nurses, physicians, physical therapists, technicians, secretaries and hospital aides. A 44-item questionnaire was completed by 1600 employees in six hospitals associated with one Turkish university using a cross-sectional survey design. Most respondents $(65.8 \%)$ had experienced low back pain, with $61.3 \%$ reporting an occurrence within the last 12 months. The highest prevalence was reported by nurses $(77.1 \%)$ and the lowest amongst secretaries $(54.1 \%)$ and hospital aides $(53.5 \%)$. In the majority of cases $(78.3 \%)$, low back pain began after respondents started working in the hospital, $33.3 \%$ of respondents seeking medical care for 'moderate' low back pain while $53.8 \%(n=143)$ had been diagnosed with a herniated lumbar disc.

Age, female gender, smoking, occupation, perceived work stress and heavy lifting were statistically significant risk-factors when 
multivariate logistic regression techniques were conducted $(P<0 \cdot 05) .{ }^{(9)}$

Another study from Malaysia, found a cumulative life-prevalence of LBP was $72.5 \%$ and the yearly prevalence was $56.9 \%$. Chronic LBP prevalence was noted $5.1 \%$ of the cases. Treatment was sought in $34.1 \%$ of LBP sufferers and $7.3 \%$ required sick leave or absence from work due to LBP. Risk factors associated with LBP were professional categories, bad body posture, lifting objects or patients and the increased levels of lifting, levels of job satisfaction and stressful job demands. $^{(13)}$

\section{Operational Definition}

\section{Low back pain}

Low back pain is pain, muscle tension, or stiffness localized below the costal margin and above the inferior gluteal folds, with or without sciatica. ${ }^{(6)}$

\section{Research question}

What is the prevalence and risk factors of low back pain among health care providers in security forces hospital?

\section{Aim}

To improve the quality of health care providers' life by knowing the risk factors that could be contributed to low back pain and avoid it.

\section{Objectives}

1. To determine the prevalence of low back pain among health care providers in security forces hospital.

2. To identify the factors that contribute to the low back pain.

\section{Methods}

\section{Study design}

It was a descriptive and analytic cross- sectional study. This design was chosen as it is best suited to health services research for being quick and cost effective. It is also appropriate for studying the prevalence of low back pain (common disease).

\section{Setting}

Security Forces Hospital in Riyadh.

\section{Target population}

Health Care Providers in Security Forces Hospital.

\section{Exclusion criteria}

- Interns that has hospital rotations during the data collection.

- Health care providers on leave.

\section{Data collection tool}

Self-administered questionnaire in English language was used and it was based on the study objectives and taking help from the previous literature. It was a well-structured questionnaire including demographic, lifestyle and occupational characteristics, as well as prevalence and risk factors of LBP.

The validity of questionnaire was reviewed by Expert orthopaedic consultant and methodologist.

\section{Sample Size}

The World Health Organization formula for calculation of sample size was used to calculate it as shown below;

$$
n=\frac{Z^{2 *}(p /(1-p))}{e^{2}}
$$

$(1.96)^{2} * 70 *(100-70) /(5)^{2}=0,806 / 0.0025=$ 322 ( required sample size).

\section{Sampling Technique}

By stratified random sampling (proportionate sample):

Sample size of each stratum is proportionate to the relative size of the stratum in the population. (Inference is easier). Selection of sample units by Systematic sampling as it gives better representativeness to each sub-group of the sample population and lowers the chances of sampling error.

\section{Study variable}

Dependent (outcome): Lower back pain.

Operational definition: Anyone suffer from LBP symptom or sign as defined above.

Independent (exposure): Age, gender, race, profession, smoking, exercise, bad body posture, performing lifting patient, knowledge and working experiences. 


\section{Data Management}

All the collected data was analyzed by using the chi square analysis (qualitative variable) and ttest (quantitative variable) in SPSS software version 20.0 for Windows. The statistical significance level was set at 0.05 .

\section{Ethical Consideration}

Ethics approval was obtained from ethics committee of the institution. Data was collected after informed consent, on pure willingness of the participants and all information was kept confidential and anonymous.

\section{Results}

In this study, a total of 284 healthcare workers completed the questionnaires. Out of which 209 (75.2\%) had suffered from lower back pain (LBP).
Demographic features are shown in Table 1 and Figure 1.

Table 1 Demography of study sample

\begin{tabular}{|l|c|c|}
\hline Demographic Features & & $\mathrm{N}(\%)$ \\
\hline \multirow{3}{*}{ Gender } & Male & $160(56.7)$ \\
\cline { 2 - 3 } & Female & $122(43.3)$ \\
\hline \multirow{5}{*}{ Race } & $<30$ Years & $97(34.2)$ \\
\cline { 2 - 3 } & $31-40$ Years & $82(28.9)$ \\
\cline { 2 - 3 } & $41-50$ Years & $59(20.8)$ \\
\hline \multirow{5}{*}{ Profession } & $>50$ years & $46(16.2)$ \\
\hline \multirow{5}{*}{ Position } & Arabian & $225(80.3)$ \\
\hline & Asian & $39(13.7)$ \\
\hline & African & $10(3.5)$ \\
\hline & Indian & $2(0.7)$ \\
\hline & European & $4(1.4)$ \\
\hline & Other & $3(1.1)$ \\
\hline & Consultant & $23(8.2)$ \\
\hline & Registrar & $36(12.7)$ \\
\hline & Resident & $43(15.1)$ \\
\hline & Nurse & $42(14.8)$ \\
\hline & Physiotherapist & $10(3.5)$ \\
\hline & Radiographer & $16(5.6)$ \\
\hline & Pharmacist & $24(8.5)$ \\
\hline
\end{tabular}

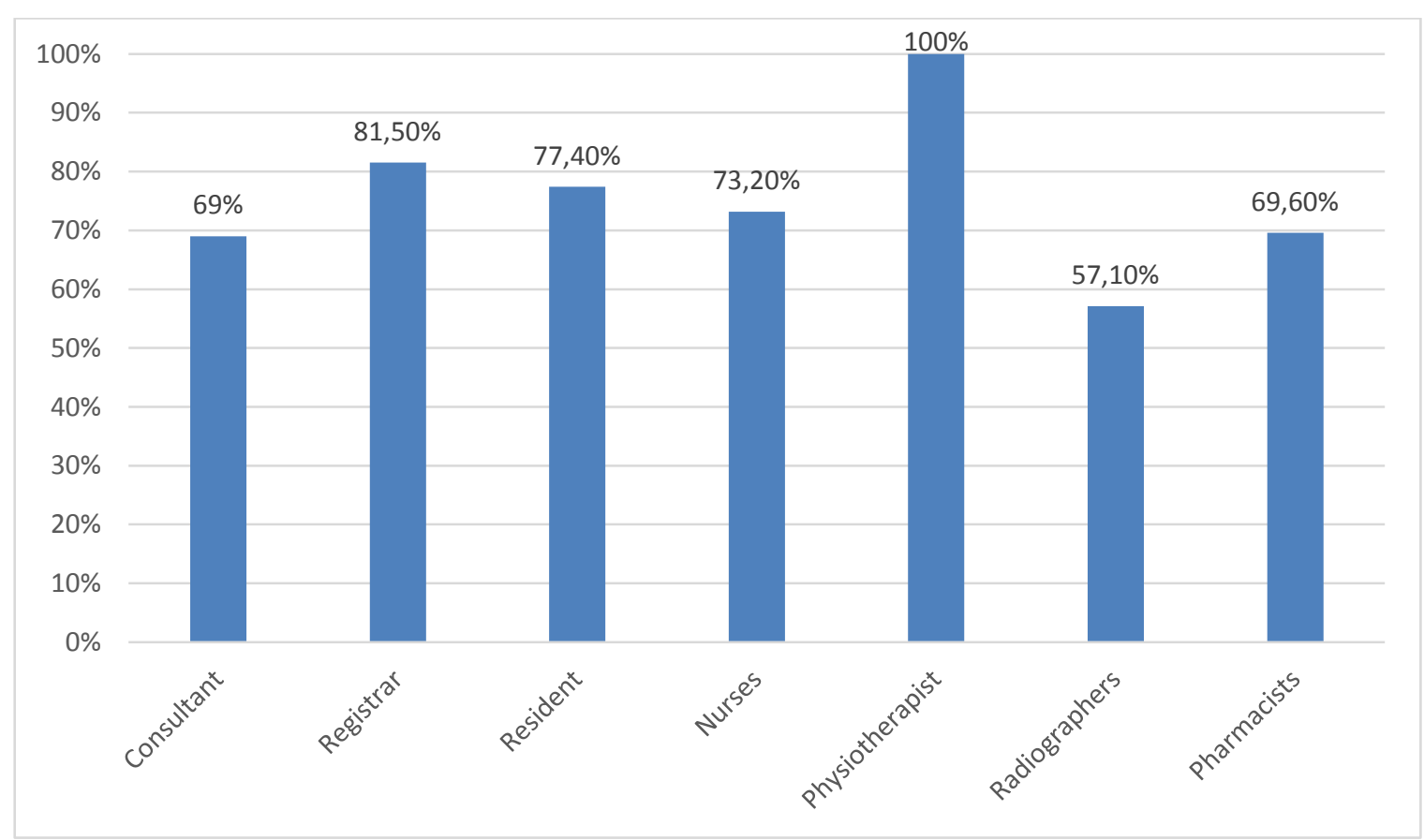

Figure 1 low back pain in health worker (\%)

In this study, $100 \%$ of physiotherapists and $57.1 \%$ of radiographers reported to have lower back pain. Among doctors, higher frequency of lower back pain was reported by registrars (81.5\%). Consultants, residents, nurses and pharmacists reported almost similar frequency of lower back pain as shown in Figure 1.

Missed data happened due to participants did not answer some questions in the questionnaire. 
Table 2 Descriptive features of LBP

\begin{tabular}{|c|c|c|}
\hline \multicolumn{2}{|l|}{ Description } & \multirow{2}{*}{$\begin{array}{c}\text { Lower Back Pain } \\
\text { Sufferers' n (\%) } \\
15(7.2)\end{array}$} \\
\hline \multirow[t]{2}{*}{ Develop LBP before or after starting job } & Before & \\
\hline & After & $194(92.8)$ \\
\hline \multirow[t]{2}{*}{ Is LBP related to work? } & Yes & $177(84.7)$ \\
\hline & No & $32(15.3)$ \\
\hline \multirow[t]{2}{*}{ Characteristics of LBP } & Localized & $185(88.5)$ \\
\hline & LBP with numbness & $24(11.4)$ \\
\hline \multirow[t]{4}{*}{ Frequency of LBP } & Daily & $29(13.9)$ \\
\hline & Weekly & $80(38.3)$ \\
\hline & Monthly & $68(32.5)$ \\
\hline & Yearly & $32(15.3)$ \\
\hline \multirow[t]{4}{*}{ Duration of LBP } & $<3$ weeks & $173(82.7)$ \\
\hline & 3-6 weeks & $25(11.9)$ \\
\hline & $6-12$ weeks & $2(0.9)$ \\
\hline & $>12$ weeks & $9(4.3)$ \\
\hline \multirow[t]{2}{*}{ Effect of LBP on life } & No effect & $154(73.7)$ \\
\hline & Yes, there is effect & $55(26.3)$ \\
\hline \multirow[t]{2}{*}{ Effect of LBP on work } & No effect & $154(73.7)$ \\
\hline & Yes, there is effect & $55(26.3)$ \\
\hline \multirow[t]{2}{*}{ Sick leave due to LBP } & Yes & $19(9)$ \\
\hline & No & $190(91)$ \\
\hline \multirow[t]{2}{*}{ Modified job due to LBP } & Yes & $23(11)$ \\
\hline & No & $186(89)$ \\
\hline \multirow[t]{2}{*}{ Treatment taken for LBP } & Yes & $100(47.8)$ \\
\hline & No & $109(52.2)$ \\
\hline \multirow[t]{3}{*}{ If treatment yes, type of treatment } & Modern & $53(53)$ \\
\hline & Traditional & $27(27)$ \\
\hline & Both & $20(20)$ \\
\hline \multirow[t]{2}{*}{ Received spine surgery } & Yes & $2(0.9)$ \\
\hline & No & $207(99.1)$ \\
\hline \multirow[t]{2}{*}{ Diagnosis of LBP from health care professional } & Yes & $32(15.3)$ \\
\hline & No & $177(84,7)$ \\
\hline
\end{tabular}

Out of $209 \mathrm{HCW}$ who reported to suffer from lower back pain, most $(194,92.8 \%)$ of them developed LBP after starting their job. Majority $(177,84.7 \%)$ said that the LBP was related to work. In $24(11.4 \%)$ HCWs, the lower back pain was associated with numbness whereas it was localized in other HWCs. Other features of lower back pain are as shown in Table 2 .

Table 3 Individual Risk Factors of LBP

\begin{tabular}{|c|c|c|c|c|}
\hline \multirow{2}{*}{\multicolumn{2}{|c|}{ Risk Factors }} & \multicolumn{2}{|c|}{ Lower Back Pain } & \multirow[t]{2}{*}{$P$ value } \\
\hline & & Yes & No & \\
\hline \multirow[t]{2}{*}{ Gender } & Male & $118(73.8)$ & $42(26.3)$ & \multirow[t]{2}{*}{0.546} \\
\hline & Female & $90(76.9)$ & $27(23.1)$ & \\
\hline \multirow[t]{4}{*}{ Age } & 21-30 Years & $66(69.5)$ & $29(30.5)$ & \multirow[t]{4}{*}{0.230} \\
\hline & 31-40 Years & $62(76.5)$ & $19(23.5)$ & \\
\hline & 41-50 Years & $48(84.2)$ & $9(15.8)$ & \\
\hline & $>50$ years & $33(73.3)$ & $13(26.7)$ & \\
\hline \multirow[t]{6}{*}{ Race } & Arabian & $164(74.9)$ & $55(25.1)$ & \multirow[t]{6}{*}{0.465} \\
\hline & Asian & $28(73.7)$ & $10(26.3)$ & \\
\hline & African & $9(90)$ & $1(10)$ & \\
\hline & Indian & $1(50)$ & $1(50)$ & \\
\hline & European & $4(100)$ & 0 & \\
\hline & Other & $2(66.7)$ & $1(33.3)$ & \\
\hline \multirow[t]{2}{*}{ Smoking } & Yes & $36(81.8)$ & $8(18.2)$ & \multirow[t]{2}{*}{0.267} \\
\hline & No & $173(73.9)$ & $61(26.1)$ & \\
\hline \multirow[t]{2}{*}{ Exercise } & Yes & $101(78.9)$ & $27(21.1)$ & \multirow[t]{2}{*}{0.154} \\
\hline & No & $105(71.4)$ & $42(28.6)$ & \\
\hline
\end{tabular}


Frequency of LBP was $73.8 \%$ among males and $76.9 \%$ among females. Age group $41-50$ years had $84.2 \%$ frequency of LBP which was higher than other age groups. Smokers had higher $(81.8 \%)$ frequency of LBP than non-smokers
(73.9\%). None of the individual risk factors (age, gender, race, smoking and exercise) were significantly associated with LBP as shown in Table 3.

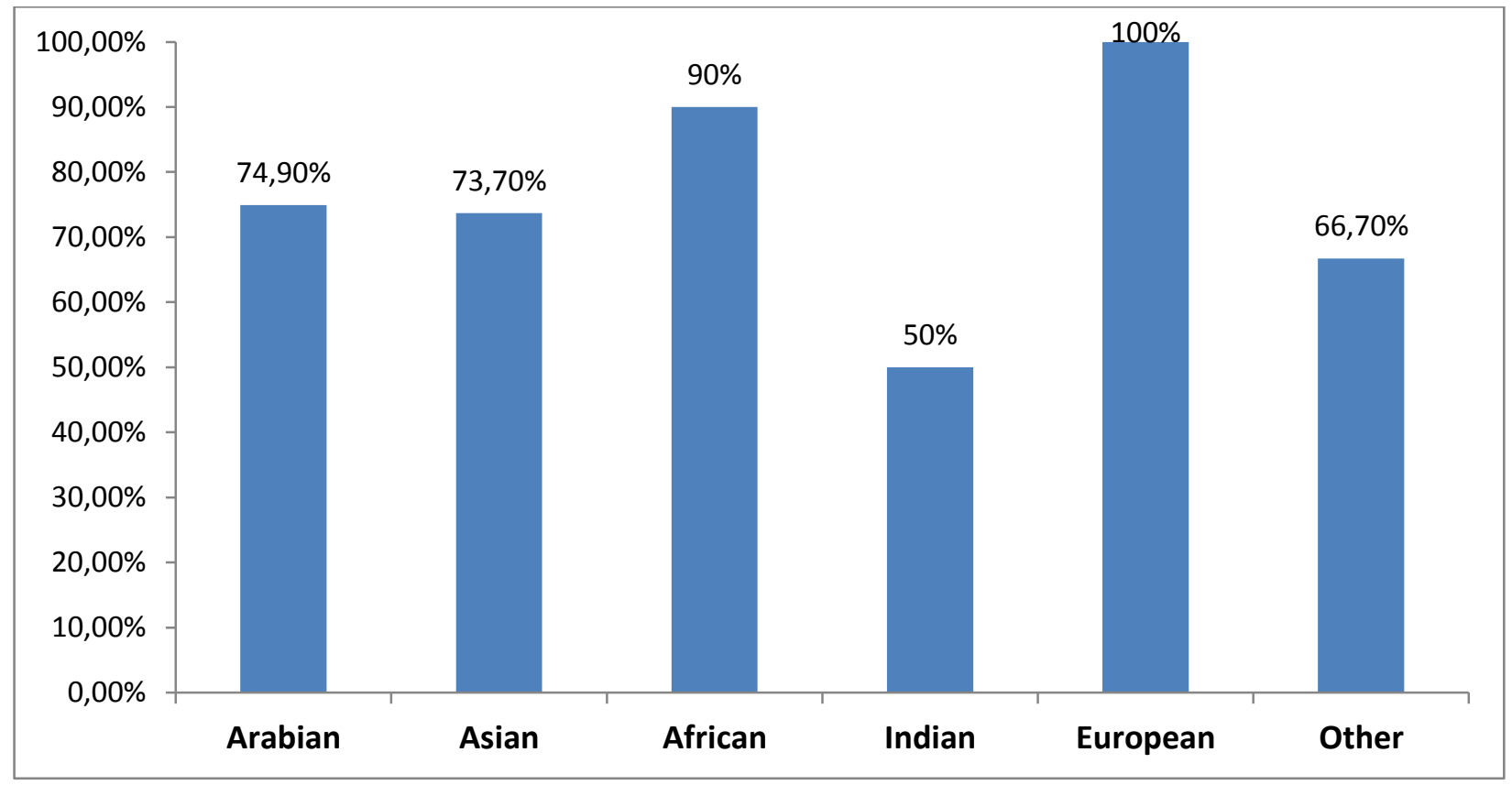

Figure 2 Low back pain in different race (\%)

In this study, $100 \%$ of European and $50 \%$ of Indian health care workers reported to suffer from LBP, whereas the frequency of LBP was $90 \%$ in
African, $74.90 \%$ in Arabian and $73.7 \%$ in Asian HCWs as shown in Figure 2. These differences were not statistically significant $(\mathrm{p}=0.465)$.

Table 4 Professional Risk factors of LBP

\begin{tabular}{|c|c|c|c|c|}
\hline \multirow{2}{*}{\multicolumn{2}{|c|}{ Risk factors }} & \multicolumn{2}{|c|}{ Lower Back Pain } & \multirow[t]{2}{*}{$\mathrm{P}$ value } \\
\hline & & Yes & No & \\
\hline \multirow{7}{*}{$\begin{array}{l}\text { Professional } \\
\text { position }\end{array}$} & Consultant & $20(69)$ & $9(31)$ & \multirow[t]{7}{*}{0.233} \\
\hline & Registrar & $22(81.5)$ & $5(18.5)$ & \\
\hline & Resident & $24(77.4)$ & $7(22.6)$ & \\
\hline & Nurse & $30(73.2)$ & $11(26.8)$ & \\
\hline & Physiotherapist & $10(100)$ & 0 & \\
\hline & Radiographer & $8(57.1)$ & $6(42.9)$ & \\
\hline & Pharmacist & $16(69.6)$ & $7(30.4)$ & \\
\hline \multirow{2}{*}{$\begin{array}{l}\text { Lifting objects or } \\
\text { patients }\end{array}$} & Yes & $78(87.6)$ & $11(12.4)$ & \multirow[t]{2}{*}{0.001} \\
\hline & No & $129(69.4)$ & $57(30.6)$ & \\
\hline \multirow[t]{2}{*}{ Bad postures } & Yes & $93(85.3)$ & $16(14.7)$ & \multirow[t]{2}{*}{0.002} \\
\hline & No & $114(68.7)$ & $52(31.3)$ & \\
\hline \multirow{3}{*}{$\begin{array}{l}\text { Knowledge about } \\
\text { LBP }\end{array}$} & Not knowledgeable & $6(40)$ & $9(60)$ & \multirow[t]{3}{*}{0.001} \\
\hline & Little knowledgeable & $79(69.9)$ & $34(30.1)$ & \\
\hline & Knowledgeable & $116(82.9)$ & $24(17.1)$ & \\
\hline \multirow[t]{5}{*}{ Working experience } & $0-5$ years & $59(68.6)$ & $27(31.4)$ & \multirow[t]{5}{*}{0.516} \\
\hline & $6-10$ years & $52(78.8)$ & $14(21.2)$ & \\
\hline & $11-15$ years & $29(76.3)$ & $9(23.7)$ & \\
\hline & $16-20$ years & $24(77.4)$ & $7(22.6)$ & \\
\hline & $>20$ years & $44(80)$ & $11(20)$ & \\
\hline
\end{tabular}


Lifting objects, bad body postures and lack of knowledge about LBP were found to be significantly associated $(\mathrm{p}$ value $=0.001,0.002$ and 0.001 respectively) with LBP. However other professional factors i.e. professional position and length of working experience had no association with LBP. Higher frequency of lower back pain was reported by physiotherapists (100\%) and registrars $(81.5 \%)$. Consultants, residents, nurses and pharmacists reported almost similar frequency of lower back pain as shown in Table 4

\section{Discussion}

Lower back pain is a very common problem in our modern society, with a prevalence rate of $70-85 \%$ in adult population ${ }^{(5,14)}$. This takes its toll on general population in terms of quality of life, productivity, absenteeism and even psychological distress. LBP is associated with multiple risk factors like age, sex, lifestyle, nature of work, knowledge about LBP, psychological profile and pain perception. Hospital workers seem to have higher rates of LBP as compared to general population due to various factors specific to their occupation $^{(9,15)}$.

In current study we found that the prevalence of LBP was $75.2 \%$. This finding is consistent with the research carried out at Zagazig University Hospitals, Egypt (79.3\%) (16) and also with a study conducted in Malaysia where life time prevalence of LBP was found to be $72.5 \%{ }^{(13)}$.

Similar results were obtained by Wong et al., in Malaysia where this percentage was $84.1 \%{ }^{(13)}$ which means our findings are in agreement with literature available. However, a comparatively lower percentage $46 \%, 57.7 \%, 60 \%$ and $61 \%$ were found by other investigators respectively. ${ }^{(17),}$ (18),(19), (20). This difference in the prevalence may explained by nature of work, different definitions of LBP or subjective perception of pain.

We found that most of the lower back pain sufferers $(92.8 \%)$ in current study developed LBP after joining the hospital and $84.7 \%$ of them think that their nature of work is the main reason of their LBP.
In current study, $88.5 \%$ complained of localized pain, and $11.4 \%$ told that the pain radiated to the lower limb. This problem was more severe in a study conducted by El-Najjar and El-Fattah who reported $68.1 \%$ localized LBP and $10.08 \%$ LBP radiating to lower limbs associated with numbness or pain radiating to the lower limbs and $7.6 \%$ complained of LBP associated with motor weakness of their lower limb muscles ${ }^{(16)}$.

When asked about the effect of LBP on their lifestyle, $26.3 \%$ agreed that it took toll on their lives and $26.3 \%$ said the same about their work. A similar study reported limitation of daily activities in $55.1 \%$ of the subjects ${ }^{(20)}$. However only $11 \%$ were modified their jobs due to LBP.

In current study, $9 \%$ of the subjects reported that they have taken sick leave due to LBP. These figures were in coherence with studies by Bejia and Al Dajah who reported $6.1 \%$ and $7.3 \%$ respectively. ${ }^{(13,18)}$ However a strikingly high figure of $53.9 \%$ was recorded in Majmaah University, AL-Majmaah, Saudi Arabia ${ }^{(20)}$. These differences may be attributed to the kind and load of work, hospital towards absentees and socioeconomic differences between the two research studies.

Out of 209 persons who had LBP just 32(15.3\%) had their problem professionally diagnosed and less than half of these sufferers had undergone treatment. Out of those who got treatment, only $53 \%$ took modern treatment while others were also relying on traditional techniques. Only $0.9 \%$ of the study population had undergone spine surgery. These results can be compared with those of Wong and Teo in Malaysia where treatment was sought in $34.1 \%$ of LBP sufferers. Interestingly, here also traditional treatments $(60.5 \%)$ were preferred over modern treatments $(27.7 \%)$, even with their easy access to modern treatments ${ }^{(13)}$. Such a high percentage of healthcare workers avoiding visit to professional doctors and sticking to the old methods of treatment in spite of all the progress we have today, shows the degree of stigma in our society. 
Moreover, it may be speculated that this issue may be even grimmer among the general population.

In our study we were not able to establish any significant relation between LBP and individual factors like; gender, age, race, smoking and exercise. However these are the questions that give most varied results. El-Najjar and Fattah links age with LBP $(P<0.02)^{(16)}$. Similarly Bejia and Omokhodion declare being female as a significant risk factor (18)(17). When it comes to tobacco Wong and Sritipsukho say there is no association $^{(13)(21)}$. However Bejia establishes a strong relationship $(P=0.016){ }^{(18)}$. Similarly some studies declare exercise irrelevant ${ }^{(13)}$ while others declare it a protecting factor against LBP $(P=$ $0.019)^{(18)}$.

When reviewing professional life, we were unable to establish any statistically significant association between LBP with position in the hospital and working experience $(\mathrm{p}=0.233$ and 0.516 respectively). Similar relationship with seniority in job was established by El Najjar and Fattah. ${ }^{(16)}$. There are some other researches which give opposite results. Wong establishes a significant relationship of $\mathrm{p}<0.001^{(13)}$ and similar results were given by $\mathrm{Bejia}^{(18)}$. Lifting objects, bad body postures and lack of knowledge about LBP were found to be significantly associated ( $\mathrm{p}$ value = $0.001,0.002$ and 0.001 respectively) with LBP. This result was augmented by many other researches on the same topic ${ }^{(17)(18)(13)(16)}$.

LBP has a high prevalence among hospital staff members and it has significant social, medical and professional consequences. Most of the individual and professional risk factors were in accordance with other studies mentioned, the remaining discrepancies sheds light on the particular demographics of the study environments. Also different definitions, norms of that particular group, subjective expression and recall bias may alter the results. The high prevalence of LBP requires multidisciplinary involvement in order to reduce the disability and cost imposed.

\section{Conclusions}

Lower back pain has high prevalence among healthcare workers. Practice regarding getting diagnosis and seeking modern treatment was suboptimal. Lower back pain was significantly associated with lifting objects, bad postures and lack of knowledge about lower back pain.

\section{Strengths and Limitations}

It was a cross sectional study. Cross sectional design may not be suitable for assessment of longterm conditions due to subjective expression and recall bias may alter the results. In this study, the participants were healthcare providers and the cross sectional design using self-administered questionnaire in English language is quick and cost effective method and owing to the nature of participants' background knowledge, language barrier, subjective expression and recall bias may not make a huge difference. All ethical considerations were taken into account. The validity of questionnaire was reviewed by Expert orthopaedic consultant and methodologist. Sample size was appropriately calculated so that results may be applicable and generalizable. A stratified random sampling was used that gives better representativeness to each sub-group of the sample population and lowers the chances of sampling error.

\section{References}

1. Hoy D, Bain C, Williams G, March L, Brooks P, Blyth F, et al. A systematic review of the global prevalence of low back pain. Arthritis \& Rheumatism. 2012;64(6):2028-37.

2. Hoy D, Brooks P, Blyth F, Buchbinder R. The epidemiology of low back pain. Best practice \& research Clinical rheumatology. 2010;24(6):769-81.

3. Hoy D, March L, Brooks P, Woolf A, Blyth F, Vos T, et al. Measuring the global burden of low back pain. Best Practice \& Research Clinical Rheumatology. 2010;24(2):155-65. 
4. Punnett L, Prüss- Ütün A, Nelson DI, Fingerhut MA, Leigh $\mathrm{J}$, Tak $\mathrm{S}$, et al. Estimating the global burden of low back pain attributable to combined occupational exposures. American journal of industrial medicine. 2005;48(6):459-69.

5. Andersson GB. Epidemiological features of chronic low-back pain. The lancet. 1999;354(9178):581-5.

6. Balagué F, Mannion AF, Pellisé F, Cedraschi C. Non-specific low back pain. The Lancet. 2012;379(9814):482-91.

7. Andersson GB. Epidemiologic aspects on low-back pain in industry. Spine. 1981;6(1):53-60.

8. Freburger JK, Holmes GM, Agans RP, Jackman AM, Darter JD, Wallace AS, et al. The rising prevalence of chronic low back pain. Archives of internal medicine. 2009;169(3):251-8.

9. Karahan A, Kav S, Abbasoglu A, Dogan N. Low back pain: prevalence and associated risk factors among hospital staff. Journal of advanced nursing. 2009;65(3):516-24.

10. El Sayyed M, Naushad T, Mathew A, Kumar P. Prevalence of Work-Related Low Back Complaints among Healthcare Professionals-A Cross-Sectional Study. Journal of Physical Therapy. 2013;7(1).

11. Landry MD, Raman SR, Sulway C, Golightly YM, Hamdan E. Prevalence and risk factors associated with low back pain among health care providers in a Kuwait hospital. Spine. 2008;33(5):539-45.

12. Mohseni-Bandpei MA, Ahmad-Shirvani M, Golbabaei N, Behtash H, Shahinfar Z, Fernández-de-las-Peñas C. Prevalence and risk factors associated with low back pain in Iranian surgeons. Journal of manipulative and physiological therapeutics. 2011;34(6):362-70.

13. Wong T, Teo N, Kyaw M. Prevalence and risk factors associated with low back pain among health care providers in a district hospital. Malaysian Orthopaedic Journal. 2010;4(2):23-8.

14. Deyo RA, Mirza SK, Martin BI. Back pain prevalence and visit rates: estimates from US national surveys, 2002. Spine. 2006;31(23):2724-7.

15. Schneider S, Randoll D, Buchner M. Why do women have back pain more than men?: A representative prevalence study in the Federal Republic of Germany. The Clinical journal of pain. 2006;22(8):73847.

16. El-Najjar A, El-Fattah N, Hassan A. Prevalence of low back pain in working nurses in Zagazig University Hospitals: an epidemiological study. Egyptian Rheumatology and Rehabilitation. 2014;41(3):109.

17. Omokhodion F, Umar U, Ogunnowo B. Prevalence of low back pain among staff in a rural hospital in Nigeria. Occupational Medicine. 2000;50(2):107-10.

18. Bejia I, Younes M, Jamila HB, Khalfallah T, Salem KB, Touzi M, et al. Prevalence and factors associated to low back pain among hospital staff. Joint Bone Spine. 2005;72(3):254-9.

19. Smedley J, Egger P, Cooper C, Coggon D. Manual handling activities and risk of low back pain in nurses. Occupational and environmental medicine. 1995;52(3):1603.

20. Al Dajah S, Al Daghdi A. Prevalence and risk factors of low back pain among nurses in Sudayr region. European Scientific Journal. 2013;9(33).

21. Sritipsukho P, Siripakarn Y. Prevalence and risk factors of low back pain among the university staff. J Med Assoc Thai. 2010;93(suppl 7):S142-S8. 